\title{
THE EFFECT OF SPEAKING ENGLISH AS A SECOND LANGUAGE ON THE STUDY OF ANATOMY AND PHYSIOLOGY IN THE NURSING PROGRAMME
}

\author{
E. M. Langtree \\ Department of Nursing* and \\ Port Shepstone Campus of KwaZulu-Natal College of Nursing \\ Port Shepstone, South Africa \\ e-mail: elly.langtree@gmail.com
}

\author{
A. Razak \\ Department of Nursing* \\ e-mail: razaka@dut.ac.za \\ F. Haffejee \\ Department of Basic Medical Sciences* \\ e-mail: firozah@dut.ac.za \\ *Durban University of Technology \\ Durban, South Africa
}

\section{ABSTRACT}

The characteristics of students entering tertiary education, including nursing programmes has changed in recent years, with a large majority studying with English as a second language (ESL). There is a high attrition of students in first year nursing education, due to failure in Anatomy and Physiology (A\&P). This study aimed to determine whether ESL affects nursing students' success in A\&P and whether there was a relationship between matric scores and those of A\&P. A quantitative descriptive survey design was used to investigate whether ESL impacts on the success of first year student nurses in A\&P. Respondents $(n=248)$ with English as a first language achieved significantly higher marks in A\&P1 than ESL students $(p=0.003)$. There was also a positive correlation between A\&P scores and matriculation points. We conclude that ESL students are disadvantaged when studying A\&P in the English language and that interventions are required to improve learning in these students.

Keywords: Anatomy and Physiology, English second language, higher education, nursing education, South Africa, student

\section{INTRODUCTION}

Globally there is a high rate of attrition of nurses in their first year of nursing education (Crow Hartman and McLendon 2009; Newton and Moore 2009). Many academic institutions 
recognise the need to reduce attrition with regard to nursing students, so as to meet the quotas required to stem the shortage of nurses in practice (Hampton 2008).

International studies have indicated that one of the factors that has a negative effect on general student success in the first year of nursing education is speaking English as a second language (ESL), that is English is not the home language of the student (Starr 2009; Scheele et al. 2011). Approximately four to eight years of conversing in a second language is necessary for most students to become sufficiently competent in that language for academic success (Abriam-Yago, Yoder and Kataoka-Yahiro 1999) as students have difficulty with speed reading and language comprehension (Olsen 2012). There is also a lack of speaking and listening proficiency which may be detrimental to students' academic success. Listening in English is demanding with students having difficulty in understanding verbal directions and terminology from lecturers. Additionally, fast paced lectures may be difficult to follow. Multiple choice questions have been identified as extremely problematic for ESL students as this type of assessment is designed to test critical thinking and decision making, in addition to testing translation and reading ability of the ESL student (Olsen 2012). It has previously been noted that ESL students are hesitant to speak in class due to feeling self-conscious about their accents and also due to a fear of not being understood (Olsen 2012). Additionally, in the study of Anatomy and Physiology (A\&P), students experience difficulty with new and complicated terminology and concepts (Johnston 2010) and as a result A\&P has been cited as the most challenging subject in the nursing programme in the United Kingdom (White and Sykes 2012).

A South African study conducted by Tshotsho (2006) identified Black students from rural areas as being more disadvantaged than urban students since they do not have exposure to spoken English or the opportunity to use the language outside the classroom. This drawback, particularly for rural students results from a lack of contact with the English language with people, television, radio or books. They also do not always have good English teachers or functional school buildings (Tshotsho 2006).

In the province of KwaZulu-Natal (KZN), South Africa, the KwaZulu-Natal College of Nursing (KZNCN), offers student nurse training at 10 campuses, where over 500 professional nurses are trained annually (Statistics South Africa 2012). This college is affiliated to both the University of Zululand and the University of KwaZulu-Natal and the majority of students entering the nursing diploma programme in KZNCN speak English as a second language with isiZulu as their first language. A problem faced at the college is that there is a high attrition rate of students in their first year of nursing education, particularly due to failure in Anatomy and Physiology (A\&P). At the college, Anatomy and Physiology is taught as one subject, which is offered over two semesters as $\mathrm{A} \& \mathrm{P} 1$ and $\mathrm{A} \& \mathrm{P} 2$. The pass rate in the subject needs improvement 
so that less students fail the first year of nursing education. This will help meet the number of nurses required by healthcare institutions (Hampton 2008).

The primary aim of this study was to determine whether ESL affects nursing students' success rate in both $\mathrm{A} \& \mathrm{P} 1$ and $\mathrm{A} \& \mathrm{P} 2$ at $\mathrm{KZNCN}$.

\section{MATERIALS AND METHODS}

A quantitative descriptive survey design was used to investigate whether speaking English as a second language impacts on the success of first year student nurses in A\&P using a survey questionnaire. Quantitative data in the form of student examination scores and responses from a structured questionnaire were obtained.

The target population for this research were student nurses, in the KZNCN training programme, who were either in the final stages of completing their first year of study or had done so in the previous eight months. This comprised a total population of 524 students. Cochrane's formula was used to calculate the sample size. A minimum of 222 participants were required. As approximately 20 per cent non-response or unusable questionnaires were anticipated, 267 student nurses were targeted and 248 completed responses were received.

Five of the nine KZNCN campuses were randomly selected using the 'goldfish bowl' technique. The campus at which the principle investigator teaches was excluded from the selection for ethical reasons. New nursing students commence training on a six-monthly cycle every January and July. Student groups commencing training in July 2012 and January 2013 were used in the study sample.

As the student numbers from these groups at the selected five campuses totalled 267, all these students were invited to participate and received a questionnaire. Participation was voluntary and no students were coerced into the study. After reading the information letter, students who agreed to participate, signed the consent form. The matriculation and A\&P1 and A\&P2 scores were obtained for each of the students in the study group.

The questionnaire was developed by the researcher from four common themes/variables that emanated from previous international and local studies that related to this study topic. The themes incorporated into the questionnaire consisted of approximately five items per area and were mostly of a Likert type structure. Other questions included simple dichotomous questions for the demographic data as well as rating and ranking scales. A combination of different types of questions increased the reliability and validity of the tool (Burns and Grove 2009). Once constructed, the questionnaire was initially interrogated by an expert/focus group and then piloted for validity and reliability prior to its use to survey study participants. The constructed questionnaire was piloted, prior to data collection, with five respondents who were not included 
in the sample group. No changes were made to the questionnaire as the pilot study population indicated understanding of the questions and experienced no difficulty with the questionnaire. On assessment, the questionnaire was effective in capturing information required for this study.

Prior to conducting the study ethical approval was obtained by the Durban University of Technology (DUT) Institutional Research Ethics Committee (IREC 052/13). Permission to conduct the research was also obtained from the KwaZulu-Natal Health Research Committee, the Acting Principal of KZNCN and all five of the principals of the campuses chosen for the study.

Data was collected over a period of 10 weeks during September and November 2013. An independent lecturer, who was not involved in the research study, administered the questionnaires. The researcher was available in a nearby room to answer any queries by respondents if necessary. Data from each questionnaire were captured electronically on an Excel spreadsheet. Results of the respondents' matriculation and Anatomy and Physiology examination were also captured.

Descriptive statistics in the form of numbers and percentages were used to describe the data. In addition, measures of central tendency, including means and standard deviation were calculated, where appropriate. In order to test for significant trends in the data, inferential statistics were applied. These included Pearson's correlation, student t-tests, ANOVA, chisquare tests, Mann Whitney test and Wilcoxon Signed-Ranks test. A p-value $<0.05$ was used to indicate significance. The analysis of data was carried out using SPSS (Statistical Package for Social Sciences) Version 17.

\section{RESULTS}

A total of 248 completed questionnaires were received. The majority of respondents were female (70.2\%), Black African (86.7\%) with isiZulu as their home language (78.6\%). Only 13.3 per cent of respondents spoke English as their first language. Most of the respondents were raised in rural areas (61.3\%; Table 1$)$ where the majority attended a rural government school (46.4\%, $n=115 ; p<0.001)$. Further demographic details are provided in Table 1.

A Mann-Whitney test revealed that the respondents who grew up in urban areas scored significantly higher marks in their final matriculation examination for both English first language $(n=66 ; p=0.05)$ and English second language $(n=182 ; p=0.03)$ than respondents who were raised in rural areas. 
Table 1: Demographics of the study population

\begin{tabular}{|l|l|l|}
\hline Gender & Male & $29.8 \%(74)$ \\
& Female & $70.2 \%(174)$ \\
\hline Age category (years) & $19-20$ & $16.5 \%(41)$ \\
& $21-22$ & $16.9 \%(42)$ \\
& $23-24$ & $19.4 \%(48)$ \\
& $24-25$ & $16.5 \%(41)$ \\
& $>26$ & $30.2 \%(75)$ \\
\hline Race & Black African & $86.7 \%(215)$ \\
& Indian & $8.9 \%(22)$ \\
& Coloured & $4 \%(10)$ \\
& White & $0.4 \%(1)$ \\
\hline Home Language & isiZulu & $78.6 \%(195)$ \\
& Xhosa & $2.8 \%(7)$ \\
& Other African language & $4.8 \%(12)$ \\
& English & $13.3 \%(33)$ \\
& Afrikaans & $0.4 \%(1)$ \\
\hline Area where raised & Urban & $38.7 \%(96)$ \\
& Rural & $61.3 \%(152)$ \\
\hline Area of secondary school & Rural government school & $46.4 \%(115)$ \\
education & Urban government school (in city/town) & $26.6 \%(66)$ \\
& Peri-urban government school (township) & $22.2 \%(55)$ \\
& Private School & $4.8 \%(12)$ \\
\hline
\end{tabular}

\section{Anatomy and Physiology results}

The mean score obtained for the A\&P1 examination was $64.5 \pm 11.0$ (range = 33-92). Sixteen participants (6.5\%) failed the examination as they attained less than 50 per cent. Eleven respondents (4.4\%) did not write the examination as either a duly performed certificate (DP) was not obtained or they were either on maternity or sick leave. There were no differences in scores between male (64.1 \pm 10.3$)$ and female respondents $(64.7 \pm 11.4 ; p=0.19)$.

In A\&P2, the mean score was $62.7 \pm 13.7$ (range $=16-93$ ) and $39(15.7 \%)$ respondents failed the examination. Four respondents (1.6\%) did not obtain a DP to write the examination and $11(4.4 \%)$ others did not write the examination for unspecified reasons. Scores in A\&P2 were not different between male (61.85 \pm 11.6$)$ and female respondents $(63.1 \pm 14.5 ; p=0.12)$.

A stepwise regression indicated that respondents with English as a first language obtained significantly higher marks in A\&P1 than those who do not speak English in their home $(p=$ 0.003). However, there was no correlation between English first language and examination results obtained in A\&P2. There was a positive correlation between A\&P1 examination results and those of A\&P2 $(p<0.001)$.

There was also a positive correlation between A\&P1 results and total matriculation points $(r=0.211 ; p=0.001)$. There was no correlation between A\&P1 results and the marks obtained in individual matriculation subjects i.e. English (first or second language), mathematics and physical science.

Results for A\&P2 were positively correlated with overall total matriculation points ( $n=$ 233; $r=0.175 ; p=0.007)$. Additionally, there was a correlation between A\&P2 results versus 
English Additional Language ( $n=172 ; r=0.56 ; p=0.022)$, Biology/Life Sciences $(n=220 ; r$ $=0.237 ; p=0.001)$ and Mathematics Literacy $(n=31 ; r=0.377 ; p=0.036)$.

\section{Respondents' perception of English as the study medium}

Results from a Wilcoxon Signed-Ranks test indicated that respondents did not have difficulty with English as the language of instruction for the course $(Z=10.76 ; p<0.001)$. Respondents indicated that interactive group work $(Z=5.938$; $p<0.001)$ and study groups $(Z=8.216$; $p<$ 0.001 ) were beneficial to their learning process. The respondents did not think that their grades would improve if the course was given in another language $(Z=8.481 ; p<0.001$ ), they understood the English spoken by lecturers $(Z=12.214 ; p<0.001)$ and were not afraid to speak in class in case of being misunderstood $(Z=3.818$; $p<0.001)$. The lecturers did not speak too fast and could be understood clearly $(Z=10.702 ; p<0.001)$.

Since 78.6 per cent $(n=196)$ of the respondents spoke English as a second language, the respondent's perception of their own competence with regard to reading, writing, understanding and comprehension of English was assessed using a self-rating scale. Results from a chi-square goodness of fit test on communication in English, showed that the majority of respondents felt their ability at reading English was 'excellent' or 'good' ( $p<0.001)$; that their writing of English was 'good' ( $p<0.001)$, their understanding of English was 'good' $(p<0.001)$ and that their comprehension of English was 'good' $(p<0.001)$. They also felt that their mathematical skills were 'good' $(p<0.001)$.

\section{Respondents' perception of Anatomy and Physiology}

The respondents indicated that their scores in A\&P would have improved if they had learned more about this subject at school $(p<0.001)$. The respondents experienced difficulty in learning many new concepts and terminology in A\&P on a daily basis $(p<0.001)$. Pearson's correlation indicated that respondents who felt that they struggled to understand the English spoken by the lecturer would have performed better in A\&P if they were not required to learn too many new and difficult terms daily, however, this was not significant $(p=0.18)$. The respondents also indicated that they would perform better in A\&P if the workload in other subjects was not very extensive $(p<0.001)$ and if more posters and models were used during instruction to help their understanding of this subject $(p<0.001)$. They also felt that the availability of a phasing in course between high school and nursing would be beneficial to their success in A\&P ( $p<$ 0.001). Many respondents indicated a preference for structured questions rather than multiple choice questions in the examinations, this was however not significant $(p=0.887)$. The majority of respondents disagreed that they would score higher grades in the subject if the delivery of lessons were kept to single periods $(p=0.774)$. 


\section{Orientation to the programme}

The respondent's prior knowledge of what to expect in the upcoming course and attending an orientation programme had a positive impact on their success. A Wilcoxon Signed-Ranks Test indicated that a significant number of respondents felt that they did not know what they were getting into before starting the nursing course $(p<0.001)$. The respondents felt that nursing was not what they expected $(p=0.038)$, and had anticipated the nursing programme to be more practical than theoretical ( $p<0.001)$. Most respondents also expected 'nursing to be an easy practical job’ $(p<0.001)$. The choice of another course at university did not take precedence over the nursing course $(p<0.001)$. Most respondents indicated that they were not only studying nursing in order to get the monthly salary $(p<0.001)$.

The Wilcoxon Signed-Ranks Test indicated that respondents found the transition from secondary school to tertiary education difficult $(p<0.001)$. They find it more difficult to achieve high academic results in the nursing programme $(p<0.001)$. The respondents felt that in the nursing programme there is a lot more work to do in a short space of time $(p<0.001)$ and that there was great academic responsibility on the student $(p<0.001)$. There was also agreement that the method of teaching is different and faster than at secondary school $(p<$ $0.001)$.

\section{DISCUSSION}

In this study, the majority of respondents speak English as their second language. Respondents who speak English as their first language perform better in A\&P1 but this correlation does not exist with the A\&P2 results. This indicates that in the first semester of study, ESL students experience difficulty with the English language which impacts on their learning, particularly with new and complicated terminology in A\&P. This effect is no longer seen in the second semester of study because by this time, these students have acquired sufficient skills in the language. In addition, they are also already familiar with anatomical and physiological terminology from their first semester of study. This would have helped to ease the learning process in the second semester and ESL learners are therefore able to cope with A\&P2 in the same manner as English first language speakers. The positive correlation of A\&P1 and A\&P2 results indicated in our study, confirm that the knowledge gained of terminology and concepts assists in future learning of the subject at a higher level.

Despite our finding of a negative correlation with ESL and A\&P1 results, most respondents assessed themselves as being 'good' at reading, writing, understanding and communicating in English on a four-point rating of their competency in the English language. 
This is perhaps related to how they view their own competency in English communication with their peers and since they are able to understand each other, they assume that they are 'good' at English. This is however, not related to the complex understanding and comprehension that is required for the study of A\&P in English. Whilst they may be able to communicate reasonably well in English to make themselves understood and to understand others, they are not yet sufficiently prepared to understand complex terminology. However, it must also be noted that the surveys were conducted after the respondents completed A\&P2 and their responses are perhaps related to their level of English proficiency at this stage and not at the beginning of their first year of tertiary education. Our results are confirmed by other studies that also indicate that students who have schooled in South Africa with English as a second language have been disadvantaged academically (Williams 2004; Tshotsho 2006; Pitman, Majhanovich and BrockUtne 2010). The majority of our respondents being Black from rural areas are within this category of students.

Although respondents in this study felt they did not experience any difficulty with English as the language of instruction for the course, they benefited from interactive group work and the study groups. A need for study groups was identified in a study relating to ESL students (Starr 2009). The benefit of interactive group work in promoting a better understanding of basic principles in science lectures has also been illustrated (Silverthorne 2006). Furthermore, students find an interactive teaching style involving online learning and face to face contact in a mixed teaching approach as a more effective teaching method for Anatomy and Physiology than the traditional lecture method (White and Sykes 2012).

Those respondents who indicated that they struggle to understand the English spoken by their lecturer in class agreed that they would do better in A\&P if there were not as many new and difficult terms to learn every day. Literature indicates that students approach the discipline of A\&P with apprehension, as they experience difficulty with the many new and complex terms and concepts that have to be learnt (Johnston 2010). Furthermore, in a study conducted by Olsen (2012), on the challenges related to ESL students, English was considered to be demanding for students as they experience difficulty understanding verbal directions and terminology from lecturers (Olsen 2012).

The ESL respondents would be in their first year of tertiary education and in their first year of experiencing an increased exposure to English as a language. They would not yet have benefitted from an increased level of communicating in this language. Previous studies indicate that four to eight years of conversing in a second language is necessary for most students to become sufficiently competent in that language to gain academic success (Scheele et al. 2011). Due to differences in culture and language barriers, some ESL nursing students are not able to 
reach their full academic potential, either during their training or upon reaching their career goals (Starr 2009; Scheele et al. 2011). A lack of speaking and listening proficiency may be detrimental to students’ academic success (Olsen 2012).

ESL students are predisposed to experiencing a heavier study workload which originates from difficulties related to understanding the work content because of problems with language, reading and writing, as well as poor study skills (Starr 2009). Students may also feel workload pressure as they experience having insufficient time with the addition of obligations and responsibilities at home (Starr 2009). In addition, our study reveals that parents of respondents whose home language was English had better qualifications than those whose home language was not English. This would have had a negative impact on the latter students as they would not have had the opportunity of being orientated and guided to the traditions of academia by close members of their families (Starr 2009; Mehta, Newbold and O’Rourke 2011; Paulynice 2011).

Furthermore, the findings of this study indicate a positive correlation between A\&P1 and Matriculation Biology/Life Sciences results. These findings are supported by international studies which indicate that competence in a prescribed pre-nursing course is a prerequisite for entry into the nursing programme as it considers an applicant's academic aptitude for nursing. Adequate grade marks in A\&P are expected from students in these prerequisite courses which are used as assessments for commencing with the nursing programme. These assessments contribute towards reducing student attrition from the nursing course. Of all the subjects taken by nursing students, A\&P has been identified as the most difficult (White and Sykes 2012). Prerequisite science course performance in students was found to be a reliable predictor of academic performance in the nursing course. It was suggested that the required grade point averages for the prerequisite prescience courses be set at a higher mark and that students who performed poorly in these courses be refused entry into the nursing programme (Potolsky, Cohen and Saylor 2003). Whilst the entrance requirements into the nursing programme increased in 2008, the requirement is still relatively low with a minimum score of 40 per cent in Science or Life Science required for entry. Increasing the minimum required score of these subjects to 50 per cent would thus be beneficial. An alternative would be to introduce a bridging course in English where anatomical terms are also introduced. The latter would benefit ESL students. The establishment of teaching and learning centres where ESL students are taught language skills such as grammar, vocabulary and pronunciation have also been found to be useful (Tshotsho, Mumbembe and Cekiso 2015). Additionally, the positive correlation between A\&P1 scores and total matriculation points is in agreement with international studies (Newton 2009; Shulruf et al. 2011). Griffiths et al. (1995) established that the best predictor for nursing 
success in students' first year of nursing was the final mark from secondary school.

Furthermore, our study indicates that respondents who grew up in urban areas scored significantly higher in both English first language and English second language in their matriculation certificate. This finding is in line with South African studies that identified Black African students from rural areas as being more disadvantaged regarding proficiency in the English language than those from urban areas (Tshotsho 2006). Black African students from rural areas are more disadvantaged with regard to hearing the spoken English language as well having reduced contact with learning opportunities via media such as television, radio and books and effective teachers (Tshotsho 2006). Despite this, we found no difference in the A\&P results of respondents from urban versus rural areas, perhaps due the large volume of new terminology that negatively affected ESL students equally from both rural and urban areas.

This study also indicates a larger percentage of female (70.2\%) compared to male student nurses. This corresponds to the gender transformation indicated in a South African national survey in 2006 which indicated that males formed 20 per cent of the student nurse population compared to 5.8 per cent of professional male nurses (Wildschut and Mqolozana 2008). We found no difference in the Anatomy and Physiology results of male compared to female student nurses indicating that gender does not affect ability to study this subject in a field dominated by females and that the increased influx of males into the student nurse population is not adversely affecting results obtained in A\&P.

We conclude that ESL students are disadvantaged when studying A\&P in the English language and that interventions are required to improve learning in these students.

\section{REFERENCES}

Abriam-Yago, K., M. Yoder and M. T. Kataoka-Yahiro. 1999. The Cummins model: A framework for teaching students for whom English is a second language. Journal of Transcultural Nursing 10(2): 143-149.

Burns, N. and S. K. Grove. 2009. The practice of nursing research: Appraisal, synthesis and generation of evidence. $6^{\text {th }}$ Edition. Philadelphia: Saunders.

Crow, S. M., S. J. Hartman and C. L. McLendon. 2009. The realistic job preview as a partial remedy for nursing attrition and shortages: The role of nursing schools. The Journal of Continuing Education in Nursing 40(7): 317-323.

Griffiths, M. J., C. A. Bevil, P. C. O’Connor and D. M. Wieland. 1995. Anatomy and physiology as a predictor of success in baccalaureate nursing students. Journal of Nursing Education 34(2): 6166.

Hampton, T. H. 2008. The early identification of students at risk, a student support model. Journal of Nursing Education 47(6): 254-259.

Johnston, A. N. B. 2010. Anatomy for nurses: Providing students with the best learning experience. Nurse Education in Practice 10: 220-226.

Mehta, S. S., J. J. Newbold and M. A. O’Rourke. 2011. Why do first generation students fail? College 
Student Journal 45(1): 20-36.

Newton, S. E. and G. Moore. 2009. Use of aptitude to understand Bachelor of Science in Nursing student attrition and readiness for the National Council Licensure Examination-Registered Nurse. Journal of Professional Nursing 25(5): 273-278.

Olsen, M. A. 2012. English-as-a-second language (ESL) nursing student success: A critical review of literature. Journal of Cultural Diversity 19(1): 26-32.

Paulynice, R. 2011. What causes many college students to fail or drop out? http://paulyniceroldens. hubpages.com/

Pitman, A., S. Majhanovich and B. Brock-Utne. 2010. English as language of instruction in Africa: Policy, power and practice, ed. B. Brock-Utne, Z. Desai, M. A. S. Qorro and A. Pitman, Vol. 5, 1-38. Rotterdam: Sense Publishers.

Potolsky, A., J. Cohen and C. Saylor. 2003. Academic performance of nursing students: Do prerequisite grades and tutoring make a difference? Nursing Education Perspectives 24(5): 246-250.

Scheele, T. H., R. Pruitt, A. Johnson and Y. Xu. 2011. What do we know about educating Asian ESL nursing students? A literature review. Nursing Education Perspectives 32(4): 224-249.

Shulruf, B., Y. G. Wang, Y. J. Zhao and H. Baker. 2011. Rethinking the admission criteria to nursing school. Nurse Education Today 31(8): 727-732.

Silverthorne, D. U. 2006. Teaching and learning in the interactive classroom. Advances in Physiology Education 30: 135-140.

Starr, K. 2009. Nursing education challenges: Students with English as an additional language. Journal of Nursing Education 48(9): 478-486.

Statistics South Africa. 2012. Census 2011 Statistical Release - South Africa. Pretoria, South Africa. Government Printer.

Tshotsho, B. 2006. An investigation into English second language academic writing for black students at the Eastern Cape Technikon. Ph.D. thesis, University of the Western Cape.

Tshotsho, B., L. Mumbembe and M. Cekiso. 2015. Language challenges facing students from the Democratic Republic of Congo in a university in South Africa. International Journal of Educational Sciences 8(3): 597-604.

White, S. and A. Sykes. 2012. Evaluation of a blended learning approach used in an Anatomy and Physiology module for pre-registration health care students. Paper presented at the The Fourth International Conference on Mobile, Hybrid and Online Learning, 1-9.

Wildschut, A. and T. Mqolozana. 2008. Shortage of nurses in South Africa: Relative or absolute. Department of Labour, 1-82.

Williams, E. 2004. Research and policy on language in education in Africa. NORRAG NEWS. Network for international policies and cooperation in education and training NN34: 34-37. 